INTERVENTIONAL CARDIOLOGY AND SURGERY

\title{
Early and late outcome of skeletonised bilateral internal mammary arteries anastomosed to the left coronary system
}

\author{
M Bonacchi, F Battaglia, E Prifti, M Leacche, N S Nathan, G Sani, G Popoff
}

Heart 2005;91:195-202. doi: 10.1136/hrt.2003.024091

\begin{abstract}
Objectives: To investigate in a retrospective study the technical aspects of using the in situ bilateral internal mammary arteries (IMAs), with the right IMA (RIMA) used for revascularisation of the circumflex system, and to evaluate early and late outcome.

Materials and methods: Between January 1997 and July 2003, 552 consecutive patients underwent grafting of the circumflex artery system with an in situ skeletonised RIMA routed through the transverse sinus (eventually retrocaval). Mean (SD) age was 63.8 (11) years. 331 (60\%) patients underwent total arterial myocardial revascularisation. Mean follow up was 26 (9) months.

Results: The success rate of skeletonised RIMA grafting to the circumflex branch was 100\%. There were 19 (3.4\%) in-hospital deaths. Perioperative myocardial infarction occurred in $12(2.2 \%)$ patients. In 155 patients undergoing postoperative angiography, two had an occluded RIMA and a string-like phenomenon was seen in three RIMA and one left IMA (LIMA). Three RIMA and three LIMA had stenotic lesions. The patency rates of RIMA and LIMA were $94 \%$ and $97.4 \%$, respectively. Strong predictors of nonfunctional IMA grafts were a recipient coronary artery diameter of $<1.5 \mathrm{~mm}(p=0.022),<60 \%$ stenosis of the recipient coronary artery $(p=0.015)$, diffuse stenotic lesions of the recipient coronary artery $(p=0.018)$, and a small IMA calibre $(p=0.0001)$. Cumulative actuarial survival at three years was $96.4 \%$ and event-free cumulative survival was $93.8 \%$. Conclusions: Use of the bilateral IMAs offers the possibility of constructing various configurations, making total arterial myocardial revascularisation possible with a minimum number of arterial conduits. Use of the skeletonised RIMA through the transverse sinus and eventually retrocavally can reach most branches of the circumflex system and is associated with an excellent patency rate. Patients who received bilateral IMA grafts for left coronary system revascularisation had improved early and late outcomes and decreased risk of death, reoperation, and angioplasty.
\end{abstract}

See end of article for authors' affiliations

Correspondence to: Dr Massimo Bonacchi, Cattedra e Scuola di Specializzazione in Cardiochirurgia, University Hospital of Florence "Careggi", Viale Morgagni, 85, 50134 Florence, Italy; mbonacchi@unifi.it

Accepted 15 April 2004

1 mproved survival, improved quality of life, and reduced late cardiac events have been documented in patients receiving a left internal mammary artery (LIMA) grafted to the left anterior descending artery (LAD) compared with patients revascularised with saphenous veins. ${ }^{1}$ To enhance such results other arterial conduits, particularly the right internal mammary artery (RIMA), have been used with excellent late outcome. ${ }^{2}$ However, the optimal RIMA configuration is not yet established. Tatoulis and colleagues ${ }^{3}$ reported that the distal obtuse marginal artery could not be readily reached with in situ RIMA grafting. Some authors have advocated use of the free RIMA to overcome the anatomical limitations of the in situ RIMA ${ }^{3}$; others anastomose the in situ RIMA to the LAD. ${ }^{5}$ Anatomical studies of cadavers have shown that any coronary artery can be reached with the in situ skeletonised RIMA. ${ }^{7}$ Others have reported satisfactory and encouraging early results of revascularising the in situ skeletonised RIMA mainly to the proximal branches of the circumflex system through the transverse sinus. ${ }^{8-14}$ Moreover, pulling the RIMA through the transverse sinus may compromise both its patency rate and blood flow capacity. ${ }^{15}$ Since 1997 we have used various new configurations for total arterial myocardial revascularisation by using the in situ skeletonised RIMA routed through the transverse sinus and eventually behind the superior caval vein. ${ }^{16-19}$

The aims of this study were, firstly, to investigate whether, by using the in situ skeletonised RIMA through the transverse sinus and eventually retrocavally, both proximal and distal major branches of the circumflex system can be reached and grafted; and secondly, to evaluate the early and late outcome in this group of patients in terms of mortality, morbidity, and internal mammary artery (IMA) patency.

\section{PATIENTS AND METHODS}

Between January 1997 and July 2003, 552 consecutive patients underwent grafting of the circumflex artery with a skeletonised in situ RIMA routed through the transverse sinus. The inclusion criterion was the presence of an angiographically graftable branch of the circumflex artery ( size $\geqslant 1.5 \mathrm{~mm}$ ). Surgeons chose skeletonised IMAs according to their own preference and the patient's stability. Diabetes, female sex, old age, and chronic obstructive pulmonary disease were not considered contraindications for use of both IMAs.

\section{Patients' characteristics}

Table 1 summarises the preoperative patient characteristics. All patients underwent preoperative angiography. The posterolateral and obtuse marginal arteries were defined based on the American Heart Association reporting system for patients with coronary artery disease..$^{20}$ The size of the perfusion areas of the recipient coronary artery was qualitatively graded as large, medium, small, or tiny (corresponding to scores of 1-4). Graftable branches were defined as those having an area scoring $1-3$ with more than $50 \%$ proximal stenosis. The primary target branch of the circumflex artery for the in situ skeletonised RIMA grafting was selected preoperatively as

Abbreviations: $C A B G$, coronary artery bypass grafting; IMA, internal mammary artery; $L A D$, left anterior descending artery; LIMA, left internal mammary artery; RIMA, right internal mammary artery 
follows: in patients with two graftable branches, the branch with the larger perfusion area was selected as the primary target; if both branches had identical perfusion areas, the distal branch (posterolateral artery) was selected as the primary target for the in situ skeletonised RIMA grafting and the other vessel was revascularised with other available conduits if indicated.

We prefer to use both IMA conduits as in situ grafts as opposed to attachment of the free RIMA to the in situ LIMA ( $\mathrm{T}$ or Y graft).

\section{Anaesthesia and cardiopulmonary bypass}

Anaesthesia was induced with fentanyl $(25-30 \mu \mathrm{g} / \mathrm{kg})$, diazepam $(0.2 \mathrm{mg} / \mathrm{kg})$, and pancuronium bromide $(0.1 \mathrm{mg} /$ $\mathrm{kg})$, and was maintained with ramifentanil ( $1-3 \mu \mathrm{g} / \mathrm{kg} / \mathrm{min})$, propofol, and isoflurane if necessary. Normothermia and intermittent anterograde/retrograde warm blood cardioplegia were used.

\section{Preparation of arterial conduits}

After a median longitudinal sternotomy, the LIMA and RIMA were harvested in a skeletonised fashion (without associated tissue and without the venae comitantes) as previously described, ${ }^{16-19}$ extending $1.5-2 \mathrm{~cm}$ below the bifurcation and continuing to the superior epigastric artery without opening the pleural cavities. The mediastinal pleura were dissected gently from the endothoracic fascia, which then was incised medially for the whole length, and the IMA and satellite veins were visualised. The IMA was separated from the chest wall and isolated from the fascia, the veins satellite, and adipose tissue. After heparinisation, the IMA's stem was left intact to allow blood to flow through it until it was ready for use and was covered with gauze impregnated with warm $\left(37-40^{\circ} \mathrm{C}\right)$ papaverine solution $(4 \mathrm{mg} / \mathrm{ml})$, which allows pharmacological dilatation. To use the distal segment, which normally has a good calibre, care is taken to obtain

Table 1 Patient's preoperative clinical characteristics

\begin{tabular}{ll}
\hline & $\mathrm{n}(\%)$ or mean \\
Variable & (SD) \\
\hline Total patients & 552 \\
Women & $132(24 \%)$ \\
Age (years) & $63.8(11)$ \\
Range (years) & $38-77$ \\
Diabetes & $126(23 \%)$ \\
Hypertension & $333(60 \%)$ \\
Smoking & $414(75 \%)$ \\
Dyslipidaemia & $204(37 \%)$ \\
Hypercholesterolaemia & $38(7 \%)$ \\
Chronic renal failure (creatinine >133 $\mu$ mol/I) & $21(4 \%)$ \\
Cerebral ischaemia & $15(2.7 \%)$ \\
Peripheral vascular disease & $33(6 \%)$ \\
Chronic obstructive pulmonary disease & $51(9.3 \%)$ \\
NYHA functional class & $1.5(0.8)$ \\
Canadian Cardiovascular Society class & $3.3(0.7)$ \\
Stable angina & $220(40 \%)$ \\
Unstable angina & $193(35 \%)$ \\
Silent angina & $36(6.6 \%)$ \\
Prior myocardial infarction & $253(46 \%)$ \\
Prior coronary angioplasty & $117(21 \%)$ \\
Heavily calcified aorta & $33(6 \%)$ \\
Previous saphenectomy or varicose saphenous vein & $38(7 \%)$ \\
Coronary angiography data & \\
Three vessel disease & $351(63.7 \%)$ \\
Two vessel disease & $200(36.3 \%)$ \\
Left main coronary artery stenosis & $143(26 \%)$ \\
LVEF < 35\% & $117(21 \%)$ \\
NYHA class >III & $108(19.7 \%)$ \\
Left ventricular ejection fraction (\%) & $49(14)$ \\
\hline LVEF, left ventricular ejection fraction; NYHA, New York Heart \\
Association. & \\
\hline
\end{tabular}

the maximum length by harvesting the RIMA near its origin. On both sides of the superior mediastinum, the pleural pericardial tissues were dissected and the IMA beds were created. Creating a bed allows the IMA to lie medially and posteriorly to the lung. Ventilation does not stretch or distort the arteries, which are protected if repeat sternotomy is required. Then the in situ skeletonised RIMA was routed retrocavally and usually superiorly to the azygous vein, which was not divided. The inside blood pressure forces the graft to orient correctly and avoids graft distortion. The size of the IMA was measured at the anastomotic site before it was anastomosed. Only IMA segments larger than $1.5 \mathrm{~mm}$ were used. Free flow in the IMA was evaluated intraoperatively in all cases: in all IMAs the free flow was $>50 \mathrm{ml} / \mathrm{min}$ and all IMAs were used. After heparin administration, the IMAs were cut, the distal ends were closed with a haemoclip, and the proximal end was clamped with a bulldog clamp. The radial artery was harvested from the non-dominant arm at the same time as the IMA was prepared. The palmar arch was assessed preoperatively with an Allen test. Digital plethysmography was done in questionable cases. The radial artery was cut bilaterally and cannulated with a $1 \mathrm{~mm}$ elastic needle through which $10 \mathrm{ml}$ of a solution containing diltiazem ( $5 \mathrm{mg} / \mathrm{ml})$ and nitroprusside $(10 \mathrm{mg} / \mathrm{ml})$ in warm Ringer solution was gently injected.

\section{Surgical techniques}

On-pump with the heart beating, the coronary arteries were explored and possible anastomosis locations were determined. The length of LIMA necessary for grafting to the LAD artery was measured and, if necessary, the remaining excessive segment of LIMA was dissected providing a free LIMA segment for composite grafts. ${ }^{16-18}$ All the IMAs' anastomoses were sutured with 8-0 polypropylene. One hundred and five patients underwent myocardial revascularisation according to previously described techniques. ${ }^{16-1821}$ The in situ LIMA was anastomosed to the LAD in all patients. The in situ RIMA was anastomosed to the most important branch of the circumflex artery (285 of 320 patients, $89 \%$ ). The second circumflex branch, depending on branch calibre and the presence of a proximal stenosis, was revascularised in 35 of 320 patients $(11 \%)$ with the radial artery ( 11 of 35 , $31 \%)$ in a $\mathrm{Y}(10$ patients, $90 \%)$ or $\mathrm{T}$ (one patient, $10 \%$ ) construction, with in situ RIMA sequential anastomosis (two of $35,5.7 \%$ ), or with a saphenous vein graft ( 12 of $35,34 \%$ ). The left ventricle was lifted and rotated to the right side to expose its lateral wall. Sewing the in situ RIMA in this position is easier than when the heart is not rotated but, on the other hand, requires additional length. The in situ RIMA may sometimes be tight during this part of the operation, but releasing the heart after completion of the anastomosis restores adequate length and loosens the tension in the graft that results from rotating the heart. The size of the recipient coronary artery was measured by passing it through a metal probe (1-2.5 mm).

One hundred and eighteen patients underwent off-pump coronary artery bypass grafting (CABG). The coronary arteries were exposed by pericardial traction sutures and immobilisation was maintained by an Octopus 1 or 2 (Medtronic) stabiliser. Intracoronary shunts were rarely used. Table 2 lists the intraoperative data. Treatment with intravenous nitro-derivates was initiated immediately after the aorta was unclamped, according to the haemodynamic situation, and was continued during the postoperative course in the intensive care unit and was eventually combined with diltiazem. The oral vasodilator was continued for almost four weeks postoperatively. 


\begin{tabular}{|ll|}
\hline Table 2 Operative data & \\
\hline Variable & $\mathbf{n}(\%)$ or mean (SD) \\
\hline Cardiopulmonary bypass time (min) & $94(18)$ \\
Aortic cross clamping time (min) & $68(12)$ \\
Off-pump CABG & $118(21.4 \%)$ \\
RIMA grafted to OM & $71(13 \%)$ \\
RIMA grafted to PL & $47(8.5 \%)$ \\
Number of distal anastomoses/patient & $3.1(0.5)$ \\
Coronary artery endarterectomy & $44(8 \%)$ \\
Sequential anastomoses & $46(8.3 \%)$ \\
With in situ RIMA & $7(1.3 \%)$ \\
Left internal mammary artery & $552(100 \%)$ \\
RIMA & $552(100 \%)$ \\
Grafted to OM & $320(58 \%)$ \\
Grafted to PL & $232(12 \%)$ \\
Both circumflex branches had almost & $28(12 \%)$ \\
identical perfusion areas & $322(58.4 \%)$ \\
Retrocaval RIMA routing & $110(20 \%)$ \\
Radial artery & $69(62.7 \%)$ \\
Grafted to right coronary artery & $41(37.3 \%)$ \\
Grafted to one of the marginal branches & $2.2(0.3)$ \\
Arterial grafts/patient & $331(60 \%)$ \\
Total arterial myocardial revascularisation & \\
Composite grafts & $87(15.7 \%)$ \\
Right Y graft & $138(25 \%)$ \\
Left Y graft & $18(3.3 \%)$ \\
Right T graft & $4(0.7 \%)$ \\
Inverted T graft & $19(3.5 \%)$ \\
Composite anastomosis ( $\Omega$ anastomosis) & $25(4.6 \%)$ \\
Associated surgical procedures & $22(4 \%)$ \\
Aortic valve replacement & $16(2.9 \%)$ \\
Mitral valve repair & $22(4 \%)$ \\
Mitral valve replacement & $5(0.9 \%)$ \\
Carotid artery endarterectomy & $6(1.1 \%)$ \\
Cholecystectomy & $17(3 \%)$ \\
Postoperative surgical procedures & \\
Revision for deep sternal wound infection & \\
Surgical revision for bleeding & \\
\hline CABG, coronary artery bypass grafting; OM, obtuse marginal artery; PL, \\
posterolateral branch of the circumflex artery; RIMA, right internal \\
mammary artery. & \\
& \\
& \\
\hline
\end{tabular}

\section{Postoperative graft evaluation and follow up}

At 6-12 months after surgery all patients underwent stress testing (dobutamine echocardiography, thallium scintigraphy, or both). Initially in our experience, we performed the postoperative angiography in all patients undergoing RIMA anastomosed to the circumflex system through the transverse sinus. Later on, owing to limited financial resources, we decided to perform the coronary angiography only in patients with doubtful results on dobutamine echocardiography or scintigraphy studies.

\section{Definitions}

Only grafts of good calibre, with no occlusion, string sign, or significant stenosis, were considered patent. In-hospital death was defined as death for any reason occurring within 30 days after operation. Perioperative myocardial infarction was defined as the appearance of new $\mathrm{Q}$ waves or significant loss of $\mathrm{R}$ wave and/or peak creatine kinase $\mathrm{MB}$ fractions greater than $10 \%$ of total creatine kinase. Low cardiac output syndrome was defined as a cardiac index $<2.0 \mathrm{l} / \mathrm{min} / \mathrm{m}^{2}$, requiring pharmacological support or intra-aortic balloon pump insertion. An $88.4 \mu \mathrm{mol} / \mathrm{l}$ increment in the postoperative creatinine concentration over the preoperative value defined postoperative renal dysfunction. Neurological complications were defined as any transient or permanent neurological deficit that developed after surgery. String sign was defined as diffuse narrowing of distal IMAs.

\section{Statistical analysis}

Group statistics were expressed as mean (SD). The generalised Wilcoxon test was used to compare groups. Fisher's
Table 3 Morbidity and in-hospital deaths

\begin{tabular}{ll}
\hline & $\mathbf{n}(\%)$ or mean \\
Variable & (SD) \\
\hline Intensive care unit stay (days) & $1.3(0.8)$ \\
Mechanical ventilation (h) & $6.5(2.7)$ \\
Prolonged ventilation (>48 h) & $12(2.2 \%)$ \\
New intra-aortic balloon pump & $11(2 \%)$ \\
New myocardial infarction & $12(2.2 \%)$ \\
Inotropic use (dopamine $>6$ mg/kg/min) & $38(6.9 \%)$ \\
Atrial fibrillation & $55(10 \%)$ \\
Other arrhythmias & $18(3.3 \%)$ \\
Bleeding >1000 ml & $44(8.8 \%)$ \\
Renal dysfunction (creatinine $>177 \mu$ mol/l) & $32(5.8 \%)$ \\
Postoperative ultrafiltration/haemodialysis & $10(1.8 \%)$ \\
Unilateral pulmonary embolism (chest $x$ ray) & $38(7 \%)$ \\
Bilateral pulmonary embolism (chest $x$ ray) & $26(4.7 \%)$ \\
Postoperative THC & $44(8 \%)$ \\
Pneumothorax & $30(5.6 \%)$ \\
Diaphragm impairment & $2(0.4 \%)$ \\
Bronchopneumonia & $17(3.1 \%)$ \\
Gastrointestinal complications & $12(2.2 \%)$ \\
Transient neurological complications & $12(2.2 \%)$ \\
Stroke & $3(0.44 \%)^{*}$ \\
Multiorgan failure & $3(0.4 \%)$ \\
Sepsis & $6(1.1 \%)$ \\
Skin layer dehiscence & $9(1.6 \%)$ \\
Deep sternal wound infection & $6(1.1 \%)$ \\
In-hospital mortality & $19(3.4 \%)$ \\
Causes of in-hospital death & \\
Acute myocardial infarction & 4 \\
Aortic dissection & 1 \\
Low cardiac output & 4 \\
Multiorgan failure & 1 \\
Sepsis & 1 \\
Permanent stroke & 1 \\
Coagulopathy/bleeding & 1 \\
\hline *One postoperative stroke was identified in one patient undergoing \\
concomitant carotid endarterectomy and the other one in a patient \\
undergoing associated mitral valve surgery. & \\
THC, thoracocentesis. & \\
& \\
\hline
\end{tabular}

exact test was used for the non-continuous variables. The relation between preoperative and postoperative variables within the same group was assessed by the McNemar test. Stepwise multiple regression analysis was used to identify predictors for non-functional IMA grafts. The cumulative risk adjusted mortality was constructed based in the Euroscore model. Long term survival rates were calculated by the Kaplan-Meier method and the long rank test. Significance was considered to be $\mathrm{p}<0.05$.

\section{RESULTS}

In all cases it was possible to anastomose the skeletonised in situ RIMA to the primary vessel target of the circumflex artery as planned preoperatively. To shorten the distance, the in situ RIMA was routed behind the superior caval vein in 322 patients. There were $19(3.4 \%)$ in-hospital deaths. Table 3 lists the causes of early death.

In 435 patients with left ventricular ejection fraction $>35 \%$ undergoing CABG alone without associated procedures, in-hospital mortality was $0.9 \%$ (four patients). Intraaortic balloon pumping was required in $11(2 \%)$ patients: three of them had a preoperative left ventricular ejection fraction $<30 \%$. Perioperative myocardial infarction occurred in $12(2.2 \%)$ patients; in five patients it was correlated with a vein graft anastomosed to a very diseased posterior interventricular artery. There were 17 (3\%) re-explorations for bleeding, but none was related to the RIMA. Postoperatively, 15 patients $(2.7 \%)$ had deep sternal wound infection or skin layer dehiscence (table 3). Only six of them were diabetic and nine non-diabetic $(\mathrm{p}=0.3)$.

To clarify the characteristics of the in situ RIMA grafting, in 155 patients undergoing postoperative angiography at a 


\begin{tabular}{|c|c|c|c|}
\hline Variable & $\begin{array}{l}\text { RIMA to circumflex } \\
(n=155)\end{array}$ & $\begin{array}{l}\text { LIMA to LAD } \\
(n=155)\end{array}$ & p Value \\
\hline Length of IMA used $(\mathrm{cm})$ & $19.2(2.6)$ & $14.2(3.5)$ & 0.001 \\
\hline \multicolumn{4}{|l|}{ IMA calibre } \\
\hline Small $(<1.5 \mathrm{~cm})$ & $11(7 \%)$ & $8(5.2 \%)$ & 0.64 \\
\hline Medium $(1.5-2.0 \mathrm{~cm})$ & $112(72 \%)$ & $100(64.5 \%)$ & 0.18 \\
\hline Large $(>2 \mathrm{~cm})$ & $32(21 \%)$ & $47(30.3 \%)$ & 0.07 \\
\hline Recipient CA $>1.5 \mathrm{~mm}$ & $129(83 \%)$ & $149(96 \%)$ & 0.001 \\
\hline \multicolumn{4}{|l|}{ Perfusion area } \\
\hline Small & $26(16.8 \%)$ & $2(1.3 \%)$ & 0.001 \\
\hline Medium & $118(76 \%)$ & $23(14.8 \%)$ & 0.001 \\
\hline Large & $11(7 \%)$ & $130(84 \%)$ & 0.001 \\
\hline \multicolumn{4}{|l|}{ Postoperative angiographic data } \\
\hline Occlusion & $2(1.3 \%)$ & 0 & 0.5 \\
\hline Stenosis & $3(2 \%)$ & $3(2 \%)$ & 1.0 \\
\hline String sign & $4(2.5 \%)$ & $1(0.6 \%)$ & 0.37 \\
\hline $\begin{array}{l}\text { Non-functioning RIMA anastomosed } \\
\text { to PL }\end{array}$ & $5(3.2 \%)$ & 0 & NA \\
\hline Off-pump CABG & 54 & 54 & \\
\hline Non-functioning IMA & 3 & - & \\
\hline Patent IMA graft & 146 (94\%) & 151 (97.4\%) & 0.26 \\
\hline
\end{tabular}

mean (SD) of 17 (5.6) months, the intraoperative data for RIMA and LIMA were compared (tables 4 and 5). As shown, the length of the in situ RIMA that was used to graft one of the circumflex system branches was longer than the in situ LIMA, indicating that the distal, smaller, muscular segment of the in situ RIMA was used. In addition, the calibre and perfusion of the RIMA recipient coronary arteries were significantly smaller than those of the LAD. In general, the in situ RIMA segment near the bifurcation was used to construct the anastomosis, whereas the in situ LIMA was anastomosed a mean (SD) of $2.7(1.1) \mathrm{cm}$ proximally to the bifurcation. The study was inadequate to evaluate the in situ RIMA in two patients, so they were excluded from the angiographic analysis. Two RIMAs were found to be occluded: the occlusion was located at the anastomosis site. The string-like phenomenon was identified in four RIMA and one LIMA. Three other RIMAs and three LIMAs had significant stenotic lesion. The total patency rates for in situ RIMA and in situ LIMA were $94 \%$ and $97.4 \%$, respectively. We considered the non-functioning grafts presenting a string sign phenomenon to be non-patent; however, these grafts may recruit their flow capacity with increasing stenotic lesion of the recipient coronary artery. ${ }^{22}$ This effect was evident in one patient with $\mathrm{T}$ graft configuration who at the postoperative angiography had a non-functioning right branch of the composite graft anastomosed to the right coronary artery. However, the graft was found to regain patency during follow up.
There were no significant differences in patency rates between in situ LIMA and in situ RIMA grafts. Strong predictors for non-functional IMA grafts were the recipient coronary artery having a diameter of $<1.5 \mathrm{~mm}(\mathrm{p}=0.022)$, $<60 \%$ stenosis of the recipient coronary artery ( $\mathrm{p}=0.015)$, diffuse stenotic lesions of the recipient coronary artery $(\mathrm{p}=0.018)$, and small IMA calibre $(\mathrm{p}=0.0001)$ (tables 4 and 5).

The remaining 376 patients underwent stress thallium-201 scintigraphy, dobutamine stress echocardiography or ergometric test within six months after surgery. None of these patients had any residual ischaemia.

The mean follow up was 26 (9) months (range 1-72 months). Cumulative actuarial survival at one, three, and five years was $99.4 \%, 96.4 \%$, and $92.5 \%$ and event-free cumulative survival was $99.4 \%, 93.8 \%$, and $89.3 \%$, respectively (fig 1 ). Figure 2 shows the cumulative risk adjusted survival according to the Euroscore. The actuarial survival did not differ between patients undergoing off-pump versus onpump CABG (fig 3).

At follow up, 10 patients underwent coronary angiography due to anginal symptoms. Two patients underwent coronary angioplasty and two patients experienced myocardial infarction. Two other patients underwent repeat CABG. These events occurred in non-revascularised coronaries or because of stenosis or occlusion of the saphenous vein graft. Another patient with left ventricular ejection fraction $<30 \%$, ischaemic mitral valve regurgitation, and a heavily calcified aorta,

Table 5 Stepwise multiple logistic regression analysis*

\begin{tabular}{lllllll}
\hline & $\boldsymbol{\beta}$ & $\boldsymbol{\beta}$ SE & $\boldsymbol{B}$ & $\boldsymbol{B}$ SE & $\boldsymbol{t}$ & $\boldsymbol{p}$ Value \\
\hline Small perfusion area & 0.048 & 0.063 & 0.037 & 0.05 & 0.77 & 0.46 \\
Small IMA calibre & 0.22 & 0.06 & 0.15 & 0.035 & 3.78 & 0.0001 \\
Recipient CA <1.5 mm & 0.16 & 0.06 & 0.13 & 0.045 & 2.5 & 0.022 \\
Stenosis of recipient CA $<60 \%$ & 0.13 & 0.056 & 0.12 & 0.048 & 2.44 & 0.015 \\
PL branch & 0.039 & 0.051 & 0.021 & 0.028 & 0.77 & 0.5 \\
Off-pump CABG & -0.013 & 0.044 & -0.011 & 0.022 & -0.07 & 0.7 \\
Diffuse stenosis recipient CA & 0.12 & 0.051 & 0.067 & 0.028 & 2.54 & 0.018 \\
Age >70 years & -0.003 & 0.055 & -0.0016 & 0.035 & -0.05 & 0.94 \\
Diabetes & 0.066 & 0.05 & 0.042 & 0.033 & 1.21 & 0.32 \\
LVEF <35\% & -0.031 & 0.055 & -0.022 & 0.04 & -0.67 & 0.41 \\
Female sex & 0.07 & 0.05 & 0.04 & 0.03 & 1.4 & 0.18 \\
Dyslipidaemia & -0.064 & 0.045 & -0.042 & 0.034 & -1.35 & 0.15 \\
\hline & *Predictors for non-functional, stenotic, or occluded internal mammary arteries at follow up assessed by stepwise \\
multiple logistic regression analysis. & & & & & & \\
\hline
\end{tabular}



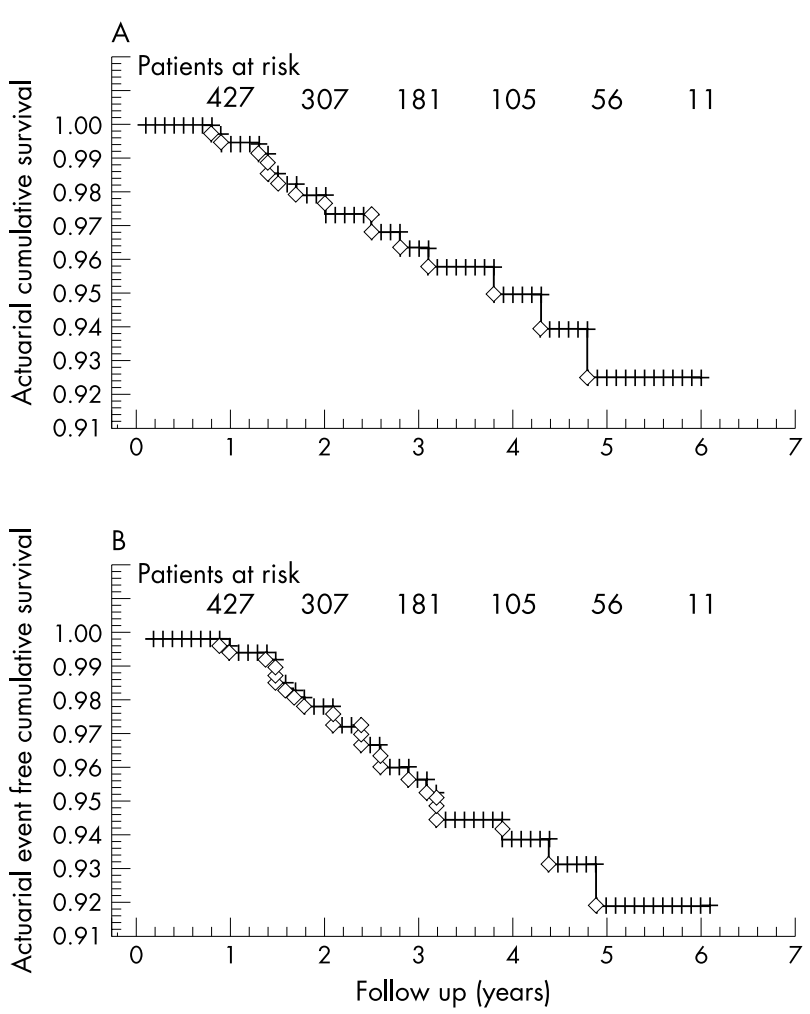

Figure 1 (A) Actuarial cumulative survival; (B) actuarial event-free cumulative survival.

who had undergone mitral valve repair at the same time as CABG, received a cardiac transplant two years after the first operation. Another patient undergoing associated aortic valve replacement required reoperation due to endocarditis. Two symptomatic patients had the string sign phenomenon in one of the IMAs.

\section{DISCUSSION}

The use of IMAs has developed in an incremental manner from anastomosing the in situ LIMA to the LAD, to the use of bilateral free or sequential IMAs, and, recently, to the use of preconstructed grafts ${ }^{23}$ due to their excellent long term patency. ${ }^{25-27}$ The in situ RIMA was found to have similar patency rates to the in situ LIMA. ${ }^{88-29}$ Various techniques have been used to harvest IMAs such as pedunculated, semiskeletonised, and skeletonised techniques. Harvesting IMAs with the skeletonised technique results in a longer arterial conduit, larger diameter, and greater flow. ${ }^{30}$ Moreover, the skeletonised technique is associated with a lower incidence of infections, ${ }^{6}$ probably due to reduced traumatic injuries of the mediastinal tissues during dissection. ${ }^{24}$ Residual side branches, suspected of causing non-functional IMA grafts, ${ }^{31}$ are easily localised by harvesting the IMA according to the skeletonised technique close to its origin and if necessary by subclavian vein mobilisation.

Bilateral in situ IMA grafting to the left coronary system has been recognised as a major determinant of survival. ${ }^{28}{ }^{32} \mathrm{~A}$ potential advantage of anastomosing both in situ IMAs to the left coronary system is that the coronary bypass flow is dependent on both IMAs simultaneously, resulting in a lower risk of hypoperfusion. Different configurations have been proposed for anastomosing both IMAs to the left coronary system; however, the best strategy has not been yet established. One option is to anastomose the in situ RIMA to the LAD and the in situ LIMA to the obtuse marginal artery. A major objection to the retrosternal in situ RIMA

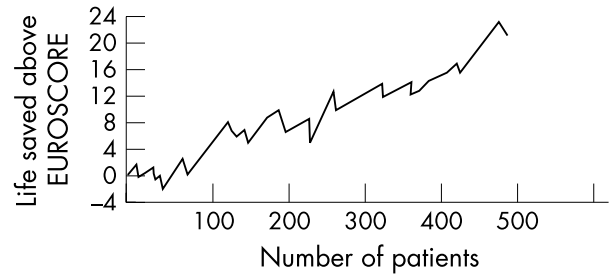

Figure 2 Cumulative risk adjusted mortality of 452 patients.

crossover route is the potential risk of damage during repeat sternotomy. ${ }^{33}$ Another possibility is to use the free RIMA, but reduced patency rates of the free RIMA have been observed when these grafts are connected proximally to the aorta. ${ }^{25}$ Attachment of the free RIMA to the in situ LIMA ( $\mathrm{T}$ or $\mathrm{Y}$ graft) may improve patency, ${ }^{27}$ but this arrangement does not apply the principle of left ventricular revascularisation from two different in situ sources, which in our opinion is a good left ventricular revascularisation strategy. In 1984, Puig and colleagues $^{34}$ reported use of the in situ RIMA through the transverse sinus for circumflex artery grafting. This configuration associated with in situ LIMA anastomosed to the LAD offers a series of advantages. First, the LAD is revascularised by the in situ LIMA, which is the ideal technique. Second, the left coronary system is perfused by two in situ IMAs. Third, it avoids the difficulties of anastomosing a thin walled vessel such as the free RIMA to a thick walled vessel such as the aorta. ${ }^{26}$ Fourth, there are no grafts crossing the midline behind the sternum and both IMAs are in a safe position, which decreases the risk of injury in case of mediastinal revision or repeat operation. Fifth, it offers the possibility of easily applying the "non-touch" principle, by using different composite graft configurations. ${ }^{16-18}$ Sixth, the calibre and flow of the distal segment of the skeletonised IMA is greater than those of the pedicled IMA. ${ }^{17}$ Lastly, fewer anastomoses are required. Other authors have hypothesised that the retroaortic course of the in situ RIMA may have some disadvantages, such as the inability to control bleeding from retroaortic in situ RIMA branches, ${ }^{15}{ }^{35}$ aortic compression of the in situ RIMA, ${ }^{35}$ and compromised graft patency because of undetected kinks and overstretching and rotation of the graft. In our experience, harvesting the RIMA by the skeletonised technique permits better localisation of the collateral branches, which are carefully clipped. In our series the postoperative bleeding rate was normal and no patient had postoperative bleeding requiring re-exploration due to

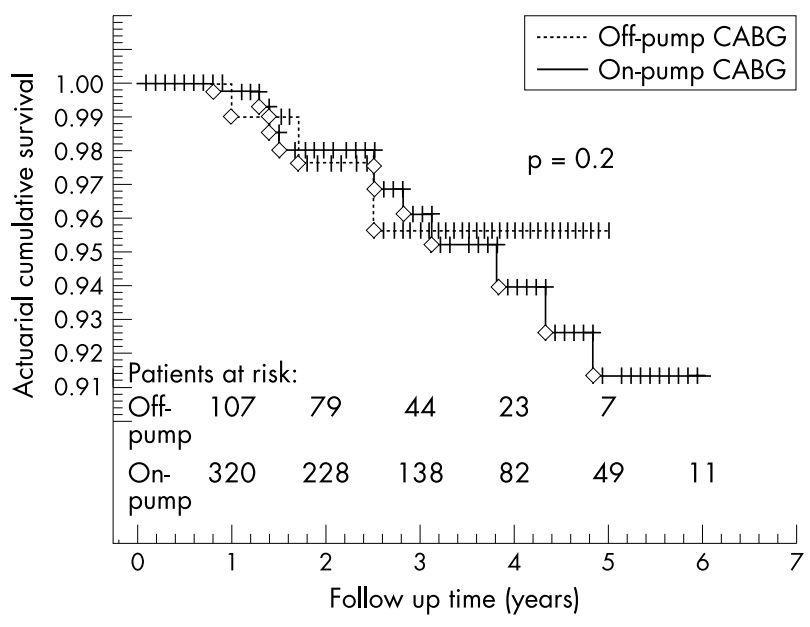

Figure 3 Actuarial cumulative survival for patients undergoing onpump and off-pump coronary artery bypass grafting. 
RIMA collateral branches. Rankin and colleagues ${ }^{35}$ in a study of a series of 20 patients receiving in situ RIMA grafts through the transverse sinus reported two RIMA occlusions and slow flow in three other patients. However, we believe that such disastrous outcomes were probably due to the technique (pedicle), to difficulties in RIMA harvesting, or to a small RIMA calibre, rather than to aortic compression, which remains possible in the larger pedicled IMA. We believe that, through IMA skeletonisation, creating a proportional pleural bed and, eventually, retrocaval routing, the possibility that a graft will kink or be compressed or overstretched during inspiration is almost impossible. In two postoperative occluded RIMAs in our series, we did not find kinking. When the in situ RIMA is anastomosed to the circumflex artery, however, once the anastomosis is completed, the course of the graft seems to be smooth due to a lack of tension or excessive motion.

In the report by Ramstrom and colleagues, ${ }^{15}$ the in situ RIMA through the transverse sinus reached only the most proximal parts of the circumflex artery; consequently, the in situ RIMA was predominantly used to revascularise the LAD. Buche and associates ${ }^{14}$ reported that only $52 \%$ of the patients undergoing circumflex bypass grafting received the in situ RIMA through the transverse sinus. They did not, however, mention the exact percentage of the in situ RIMA that could not be used because of anatomical limitations in the remaining $48 \%$ of patients. Tatoulis and colleagues, ${ }^{3}$ reporting on 1454 free RIMA grafts, of which 552 were anastomosed to the first obtuse marginal artery and 166 to the second obtuse marginal artery, confirmed the opinion that anastomosing this graft to the obtuse marginal artery is the best alternative; however, those authors believe that the in situ RIMA was not long enough to graft to these vessels. In our experience we have not found it difficult to graft the in situ RIMA to the obtuse marginal artery. This may result from differences in our surgical strategy or from the RIMA harvesting technique. In our practice, to use the distal RIMA segment with an acceptable calibre, care is taken to obtain the maximum length by harvesting the RIMA near its origin from the subclavian artery and to obtain the shortest route by creating an IMA bed and using the transverse sinus route. Routing the in situ RIMA behind the superior caval vein and further into the transverse sinus provides additional length, facilitating lateral coronary artery grafting through a less circuitous and a more protected route. ${ }^{36}$ Such a strategy provides an adequate length without opening the pleura. Respecting pleural integrity during the IMA harvesting procedure improves postoperative pulmonary function. ${ }^{19}$

Another controversial point is the use of the distal RIMA portion. As shown in our study the used RIMA was significantly longer than the LIMA in the same patient. We routinely have used the distal portion of the RIMA. Dietl and colleagues $^{37}$ reported an increased rate of RIMA graft failure when it is used to bypass the right coronary and posterior descending arteries, attributing this problem to spasm of the distal end of the RIMA graft. Morin and colleagues ${ }^{38}$ reported a low patency rate for the two terminal branches of the IMA used in coronary grafting. The two branches of the IMA are muscular arteries, with occasional elastic lamellae, although the mid-portion of the main IMA is more elastic. He and associates $^{39}$ reported increased contractility of the IMA towards the distal end; however, they also mentioned that data are insufficient to show that extensive use of the distal section of the IMA increases the likelihood of spasm or graft failure. Our present study showed that the use of the skeletonised distal segment of the in situ RIMA did not increase graft failure rate, at least in the early period, as long as an IMA with adequate flow and calibre is used. The high graft failure rate of bypass using the terminal branches is probably not due to a greater likelihood of contraction or spasm but to technical difficulties such as small diameter or increased graft tension. ${ }^{11}$

In our practice we routinely used skeletonised in situ RIMA grafting through the transverse sinus and eventually retrocavally for circumflex revascularisation as a complement to in situ LIMA to LAD grafting. ${ }^{17-20}$ We have never changed the target vessel because of length inadequacy, and the success rate of anastomosing the preoperatively targeted vessel was $100 \%$, even though much of the target coronaries consisted of distal branches of the circumflex artery. On the basis of our data, we can confirm that under cardioplegic arrest or with a beating heart, the skeletonised in situ RIMA passed through the transverse sinus can reach most branches of the circumflex artery, even the most distal ones such as the posterolateral branches.

The early postoperative outcome was excellent, taking into consideration that almost $21 \%$ of patients had impaired left ventricular function and almost $16.3 \%$ underwent combined surgery. The predictors of poor postoperative survival were similar to those of patients undergoing conventional CABG. In creating the shortest route, the in situ RIMA can be anastomosed with excellent results to the target coronary artery, even in high risk groups, such as women, smaller people, and elderly patients, confirming the outcome. Authors' opinions differ regarding the use of the in situ RIMA through the transverse sinus in female or smaller patients. Some studies have shown that in situ RIMA length was not adequate for grafting to the obtuse marginal artery in this subgroups of patients. ${ }^{31}{ }^{39}$ Ura and colleagues ${ }^{11}$ in a series of 393 in situ RIMA harvested according to the pedunculated technique, did not find it difficult to anastomose this graft through the transverse sinus to the circumflex artery, even in smaller patients. Also, the incidence of deep sternal wound infection in this series was low (1.1\%) indicating that the use of both IMAs and the described harvesting technique do not increase the incidence of postoperative deep sternal wound infection and other complications as previously reported..$^{25-28}$ Although during the study period most of the patients underwent bilateral IMA grafting, analysis of our results and comparison with previous reports shows that perioperative mortality is comparable and the overall incidence of unfavourable events seems to be relatively low. Despite a short follow up, patients undergoing total arterial myocardial revascularisation had a better event-free survival, probably because total arterial myocardial revascularisation was preferred for young patients with good preoperative left ventricular function. Initially in our experience, in patients older than 70 years, we have successfully used both IMAs when a heavily calcified aorta or varicose saphenous veins or saphenectomy was present. Later on, we routinely used both IMAs in this age group, believing that this strategy reduces the cardiopulmonary bypass time (fewer anastomoses to be constructed) and aortic manipulation.

Angiographic evaluation was performed prospectively in 155 consecutive patients. Our results confirm the outcome of previously reported studies independently of the study population characteristics. ${ }^{8-14}$ Galbut and colleagues ${ }^{40}$ reported increased progressive use of the in situ RIMA through the transverse sinus with good late patency rate and survival. Ura and colleagues, ${ }^{11}$ in a series of 381 of 393 patients undergoing in situ RIMA grafting through the transverse sinus, found $97.2 \%$ and $94.1 \%$ patency rates of the in situ LIMA and in situ RIMA, respectively. Ueyama and associates ${ }^{9}$ found that $97.4 \%$ of in situ RIMAs brought through the transverse sinus were patent during the early postoperative course. Buche and colleagues ${ }^{14}$ found 73 patent in situ RIMAs in 74 patients undergoing angiography at a mean of 13.2 months after operation in a series of 256 
patients undergoing in situ RIMA grafting through the transverse sinus. In our series 13 IMAs were found to be non-functional.

Interestingly, age $>70$ years was not identified as an independent risk factor for non-functional IMAs. The predictors of non-functional IMAs were small recipient coronary artery calibre, moderate stenosis of the recipient coronary artery, and diffuse stenotic lesions of the recipient coronary artery. A possible hypothesis for the low flow in the IMAs in such conditions is that there is a size mismatch between the graft and recipient coronary artery. Other factors that may induce non-functional IMAs are the possibility of medial necrosis and fibrosis secondary to the ischaemic insult of mobilisation. Large IMA side branches have been suspected of diverting blood away from the myocardium, but no cause and effect relation has ever been established. ${ }^{32}$ In our series, none of the IMAs had residual side branches, showing the superiority of the skeletonised harvesting technique. Other variables associated with graft failure are moderate stenotic native lesion of $<60 \%$ and diffuse sclerosis of the native vessels. Such results seem to be similar to the previously reported studies. ${ }^{41}$

\section{Study limitations}

Firstly, this was not a randomised study. Secondly, the target vessels were determined mainly by the perfusion area of the recipient artery and not selected randomly. Thirdly, not all the patients underwent postoperative angiography, mainly because financial resources were limited and some patients did not provide consent. Lastly, in all cases surgeons preferred to use both IMAs.

We may conclude that this study satisfactorily shows that in situ RIMA grafting is feasible in a wide variety of patients with a diseased circumflex artery. The skeletonised in situ RIMA passed through the transverse sinus and eventually retrocavally can reach most branches of the circumflex artery and is associated with an excellent patency rate. The predictors for non-functional IMAs were small calibre of the IMAs and the recipient coronary artery, moderate stenosis of the recipient coronary artery, and diffuse stenotic lesions of the recipient coronary artery. We have applied this strategy to a wide variety of patients with a diseased circumflex artery: the presence of diabetes, severe obesity, small body size, chronic obstructive pulmonary disease, female sex, age, and left ventricular dysfunction seem not to be critical contraindications to such a strategy. The use of bilateral IMAs and in situ RIMA grafting through the transverse sinus offers the possibility of constructing various configurations, making total arterial myocardial revascularisation possible with a minimum number of arterial conduits.

\section{Authors' affiliations \\ M Bonacchi, F Battaglia, E Prifti, G Sani, Department of Cardiac Surgery, University of Florence, Florence, Italy \\ M Leacche, N S Nathan, Brigham and Women's Hospital, Harvard University, Boston, Massachusetts, USA \\ G Popoff, Villa Maria Beatrice Hospital, Florence, Italy}

\section{REFERENCES}

1 Fiore AC, Naunheim KS, Dean P, et al. Results of internal thoracic artery grafting over 15 years: single versus double grafts. Ann Thorac Surg 1990;49:202-9.

2 Pick AW, Orszulak TA, Anderson B, et al. Single versus bilateral internal mammary artery grafts: 10-year outcome analysis. Ann Thorac Surg 1997; 64:599-605.

3 Tatoulis J, Buxton BF, Fuller JA. Results of 1454 free right internal thoracic artery-to-coronary artery grafts. Ann Thorac Surg 1997;64:1263-9.

4 Loop FD, Lytle BW, Cosgrove DM, et al. Free (aorta-coronary) internal mammary artery graft: late results. J Thorac Cardiovasc Surg 1986;92:827-31.
5 Lev-Ran O, Pevni D, Matsa M, et al. Arterial myocardial revascularization with in situ crossover right internal thoracic artery to left anterior descending artery. Ann Thorac Surg 2001;72:798-803.

6 Sofer D, Gurevitch J, Shapira I, et al. Sternal wound infection in patients after coronary artery bypass grafting using bilateral skeletonized internal mammary arteries. Ann Surg 1999;229:585-90.

7 Salm TJV, Chowdhary S, Okike ON, et al. Internal mammary artery grafts, the shortest route to the coronary arteries. Ann Thorac Surg 1989:47:421-7.

8 Buxton BF, Ruengsakulrach P, Fuller J, et al. The right internal thoracic artery graft: benefits of grafting the left coronary system and native vessels with a high grade stenosis. Eur J Cardiothorac Surg 2000;18:255-61.

9 Ueyama K, Sakata R, Umebayashi Y, et al. In situ right internal thoracic artery graft via transverse sinus for revascularization of posterolateral wall: early results in 116 cases. J Thorac Cardiovasc Surg 1996;1 12:731-6.

10 Gerola LR, Puig LB, Moreira LF, et al. Right internal thoracic artery through the transverse sinus in myocardial revascularization. Ann Thorac Surg 1996;61:1708-13.

11 Ura M, Sakata R, Nakayama Y, et al. Analysis by early angiography of right internal thoracic artery grafting via the transverse sinus: predictors of graft failure. Circulation 2000;101:640-6.

12 Ura M, Sakata R, Nakayama Y, et al. Technical aspects and outcome of in situ right internal thoracic artery grafting to the major branches of the circumflex artery via the transverse sinus. Ann Thorac Surg 2001:71:1485-90.

13 Corbineau H, Verhoye JP, Langanay T, et al. Feasibility of the utilisation of the right internal thoracic artery in the transverse sinus in off pump coronary revascularisation: early angiographic results. Eur J Cardiothorac Surg $2001 ; 20: 918-22$

14 Buche M, Schroeder E, Chenu P, et al. Revascularization of the circumflex artery with the pedicled right internal thoracic artery: clinical functional and angiographic midterm results. J Thorac Cardiovasc Surg 1995; 110:1338-43.

15 Ramstrom J, Lund O, Cadavid E, et al. Right internal mammary artery for myocardial revascularization: early results and indications. Ann Thorac Surg 1993;55: 1485-92.

16 Bonacchi M, Prifti E, Salica A, et al. Right Y graft technique for total arterial myocardial revascularization: a new surgical technique. Ann Thorac Surg 2000;70:820-3.

17 Prifti E, Bonacchi M, Frati G, et al. Lambda graft with the radial artery or free left internal mammary artery anastomosed to the right internal mammary artery: flow dynamics. Ann Thorac Surg 2001;72:1275-81.

18 Bonacchi M, Prifti E, Frati G, et al. Total arterial myocardial revascularization using internal mammary and/or radial arteries conduits according the new composite graft technique. J Card Surg 1999;14:408-16.

19 Bonacchi M, Priffi E, Giunti G, et al. Respiratory dysfunction after coronary artery bypass grafting employing bilateral internal mammary arteries: the influence of intact pleurae. Eur J Cardiothorac Surg 2001;19:827-33.

20 Austen WG, Edwards JE, Frye RL, et al. A reporting system on patients evaluated for coronary artery disease. Report of the Ad Hoc Committee for Grading of Coronary Artery Disease, Council on Cardiovascular Surgery, American Heart Association. Circulation 1975;51(suppl 4):5-40.

21 Bonacchi M, Prifti E, Giunti G. The " $\omega$-anastomosis", a new revascularization technique for coronary bifurcations. Ann Thorac Surg 2003;76:954-5.

22 Bonacchi M, Priffi E, Giunti G, et al. Restoration of patency after apparent occlusion of the lambda-graft's right branch. Heart Vessels $2001 ; 16: 20-2$.

23 Tector AJ, Kress DC, Downey FX, et al. Complete revascularization with internal thoracic artery grafts. Semin Thorac Cardiovasc Surg 1996;8:29-41

24 Calafiore AM, Vitolla G, laco AL, et al. Bilateral internal mammary artery grafting: midterm results of pedicled versus skeletonized conduits. Ann Thorac Surg 1999;67:1637-42.

25 Fiore AC, Naunheim KS, Dean P, et al. Results of internal thoracic artery grafting over 15 years: single versus double grafts. Ann Thorac Surg 1990;49:202-9.

26 Calafiore AM, Di Giammarco G, Luciani N, et al. Composite arterial conduits for a wider arterial myocardial revascularization. Ann Thorac Surg 1994:58:185-90.

27 Calafiore AM, Contini M, Vitolla G, et al. Bilateral internal thoracic artery grafting: long-term clinical and angiographic results of in situ versus $Y$ grafts. J Thorac Cardiovasc Surg 2000;120:990-6.

28 Schmidt SE, Jones JW, Thornby Jl, et al. Improved survival with multiple leftsided bilateral internal thoracic artery grafts. Ann Thorac Surg 1997;64:9-15

29 Dion R, Glineur D, Derouck D, et al. Long-term clinical and angiographic follow-up of sequential internal thoracic artery grafting. Eur J Cardiothorac Surg 2000;17:407-14.

30 Gurevitch J, Paz Y, Shapira I, et al. Routine use of bilateral skeletonized internal mammary arteries for myocardial revascularization. Ann Thorac Surg 1999:68:406-12.

31 Hartz RS, Heuser RR. Embolization of IMA side branch for post-CABG ischemia. Ann Thorac Surg 1997;63:1765-6.

32 Buxton BF, Komeda M, Fuller JA, et al. Bilateral internal thoracic artery grafting may improve outcome of coronary artery surgery. Circulation 1998;98:11-6.

33 Joyce FS, McCarthy PM, Taylor PC, et al. Cardiac reoperation in patients with bilateral internal thoracic artery grafts. Ann Thorac Surg 1994;58:80-5. 
34 Puig LB, Franca Neto L, Rati $M$, et al. A technique of anastomosis of the right internal thoracic mammary artery to the circumflex artery and its branches. Ann Thorac Surg 1984;38:533-4.

35 Rankin JS, Newman GE, Bashore TM, et al. Clinical and angiographic assessment of complex mammary artery bypass grafting. J Thorac Cardiovasc Surg 1986;92:832-46.

36 Pliam MB, Zapolanski A. Retrocaval routing of the right internal thoracic artery. Ann Thorac Surg 1993;56:181-2.

37 Dietl CA, Benoit $\mathrm{CH}$, Gilbert $\mathrm{CL}$, et al. Which is the graft of choice for the right coronary and posterior descending arteries? Comparison of the right internal mammary artery and the right gastroepiploic artery. Circulation 1995;92(suppl II):92-7.
38 Morin JE, Hedderich G, Poirier NL, et al. Coronary artery bypass using internal mammary artery branches. Ann Thorac Surg 1992;54:911-4.

39 He GW, Ryan WH, Acuff TE, et al. Greater contractility of internal mammary artery bifurcation, possible cause of low patency rates. Ann Thorac Surg 1994;58:529-32.

40 Galbut DL, Traad EA, Dorman MJ, et al. Coronary bypass grafting in the elderly: single versus bilateral internal mammary artery grafts. J Thorac Cardiovasc Surg 1993;106:128-36.

41 Hashimoto $\mathrm{H}$, Isshiki $\mathrm{T}$, Ikari $\mathrm{Y}$, et al. Effects of competitive blood flow on arterial graft patency and diameter. J Thorac Cardiovasc Surg 1996; 111:399-407.

\section{IMAGES IN CARDIOLOGY}

Coronary artery spasm in lymphocytic myocarditis: a rare cause of acute myocardial infarction

A

40 year old woman developed severe chest discomfort associated with dyspnoea. Her only risk factor was smoking. The ECG showed anterior ST elevation (panel A). Symptoms persisted despite treatment with oxygen, aspirin, intravenous glyceryl trinitrate, metoprolol, and heparin. Emergency cardiac catheterisation revealed normal coronary arteries (panels B and C). The left ventricle (LV) was akinetic/dyskinetic except for the basal segments (panels D and E). Her symptoms and ECG changes resolved gradually. Serial cardiac biomarker elevations were typical of acute myocardial infarction.

On day 3, an echocardiogram showed a small pericardial effusion. The distal two thirds of the LV was still akinetic/ dyskinetic. A right ventricular biopsy showed foci of lymphocytic infiltrate, some in association with myocyte damage (panels $F$ and $G$ ). These findings were consistent with the diagnosis of lymphocytic myocarditis.

On day 6, the patient was discharged on medical treatment. Ten hours later she developed recurrent symptoms. The ECG showed anterior ST elevation, unresponsive to intravenous glyceryl trinitrate or diltiazem. At repeat cardiac catheterisation there was severe spasm of the left anterior descending (LAD) coronary artery (panel $\mathrm{H}$ ). Intracoronary vasodilators were administered without success. Balloon dilatation of the LAD was needed to restore flow.

This patient had coronary vasospasm in the setting of lymphocytic myocarditis. Myocarditis occasionally presents as or mimics acute myocardial infarction, but associated coronary spasm has rarely been documented. Caution should be exercised when attributing myocardial infarction to the myocarditis alone, especially if there is ST elevation. Coronary arteriography should be performed early and provocative studies for vasospasm done in the convalescent phase if diagnostic uncertainty persists.
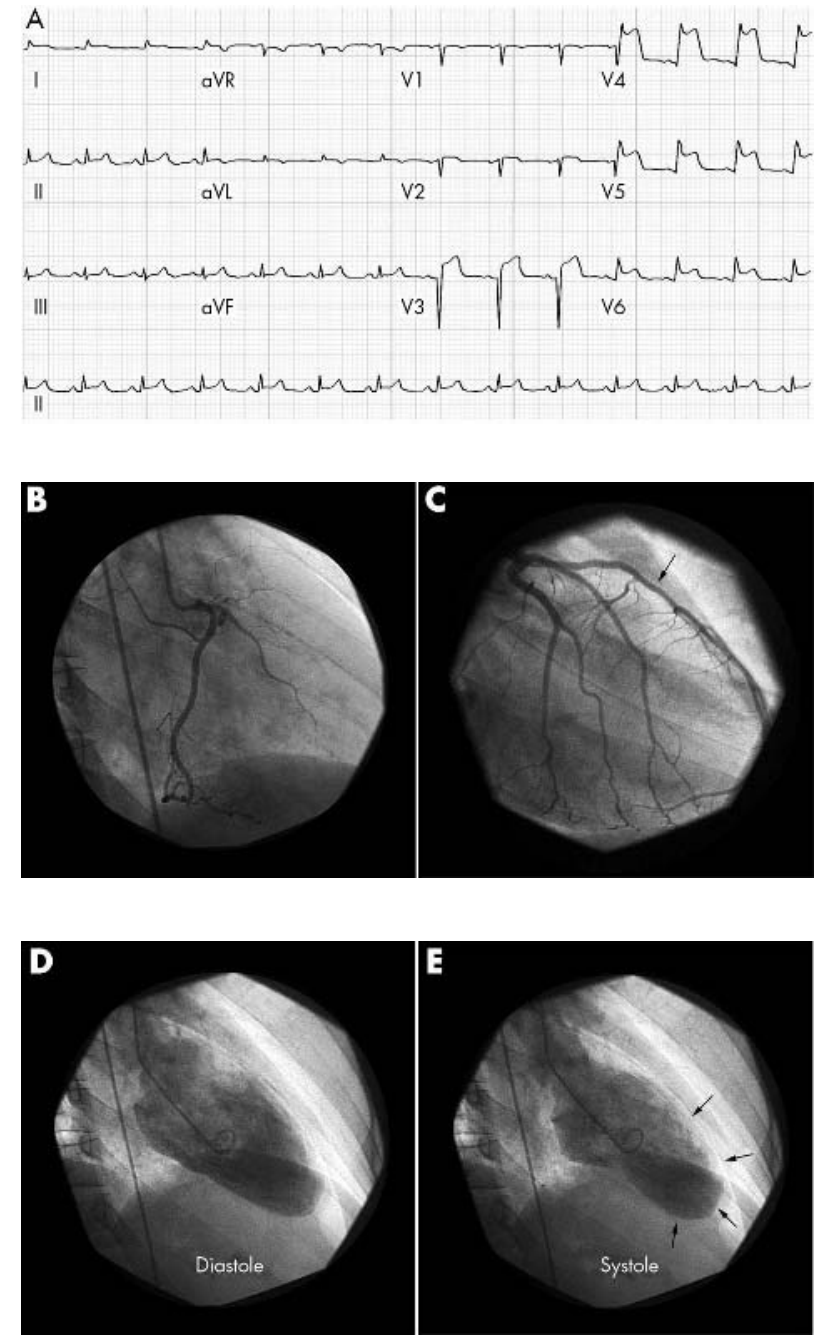

mccully.robert@mayo.edu

L T Cooper
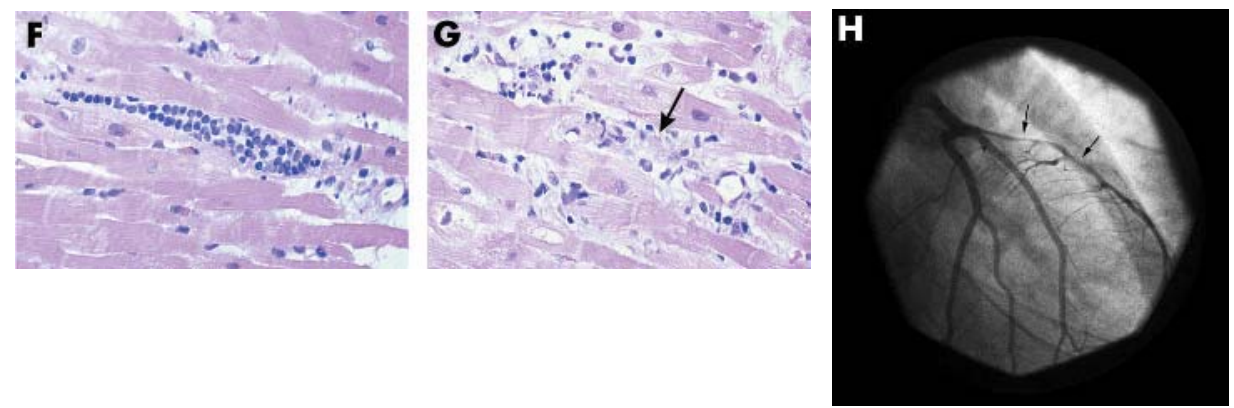